\title{
LA “PSEUdONEUTRALIDAD” LEGISLATIVA, LA FALTA DE PERSPECTIVA DE GÉNERO PARA GARANTIZAR EL ACCESO A LA JUSTICIA Y LA CONSTITUCIÓN DE LAS MUJERES VÍCTIMAS DE VIOLENCIAS COMO COLECTIVO VULNERABLE
}

\author{
Julieta Evangelina Cano \\ cano.julieta@gmail.com \\ Universidad Nacional de La Plata (Argentina)
}

Recibido: 27-02-2015

Aceptado: 26-04-2015

\section{Resumen}

El presente trabajo aborda la problemática del acceso a la Justicia para mujeres víctimas de violencias en Argentina. Recuperando posiciones de la teoría feminista, analiza si en el país se da o no, lo que se denomina una "pseudoneutralidad" legislativa que ignora las desigualdades entre varones y mujeres que sustentan el patriarcado y que además son consecuencia directa de éste. Describe y recorre la normativa específica del caso, tanto en el ámbito nacional como internacional, para reflexionar sobre si las mujeres pueden pensarse como integrantes de un colectivo vulnerable aún en un país comprometido normativamente con la igualdad.

Palabras clave: Acceso a la Justicia, violencias contra las mujeres, mujeres víctimas de violencias, colectivo vulnerable, "pseudoneutralidad" legislativa.

\begin{abstract}
This paper addresses the problem of access to justice for women victims of violence in Argentina. Retrieving positions of feminist theory, it examines if in the country occurs what is called a legislative "pseudoneutralit" that ignores the inequalities between men and women that sustain patriarchy and are also a direct result of this. It describes the specific law, both nationally and internationally, to reflect on whether women can be thought of as members of a vulnerable group even in a country committed to gender equality.
\end{abstract}

Keywords: Access to justice, violence against women, women victims of violence, vulnerable group, legislative "pseudoneutrality". 


\section{Introducción}

Frances Olsen (2009) establece que nuestras sociedades están constituidas en pares duales, sexualizados y jerarquizados ${ }^{1}$, e identifica al derecho con el lado masculino del par dual: "Se supone que el derecho es racional, objetivo, abstracto y universal, tal como los hombres se consideran a sí mismos. Por el contrario, se supone que el derecho no es irracional, subjetivo o personalizado, tal como los hombres consideran que son las mujeres" (Olsen, 2009:140).

La autora advierte que aunque el derecho se auto atribuye las características enunciadas en el párrafo anterior, cuando se ocupa de las mujeres no cumple con su objetivo. Dentro de esta crítica feminista se denuncia que para que el derecho sea verdaderamente neutral debería tener en cuenta "la actual subordinación de las mujeres y elaborar normas cuidadosamente diseñadas para rectificar y superar esta injusta desigualdad" (Olsen, 2009:147) ${ }^{2}$. Estamos de acuerdo que existen dos tipos de igualdad: la igualdad formal y la igualdad material o sustancial y en esta línea, compartimos la postura con "las feministas que abogan por el "tratamiento especial" (que) reclaman un resultado verdaderamente neutro y denuncian la falsedad de ciertas instancias de la igualdad formal, calificándolas de "seudoneutralidad"” (Olsen, 2009:148).

A pesar de que tanto las mujeres como los varones somos considerados/as dentro del colectivo de seres humanos/as, fue necesario celebrar a nivel internacional una serie de tratados que garanticen dicha igualdad y que además consagren expresamente el derecho de las mujeres a vivir una vida libre de violencias. En este marco la tesis enunciada por Olsen se vuelve pertinente: para que la igualdad formal se traduzca en igualdad material, trascendiendo la “pseudoneutralidad", es importante prestar atención a las relaciones de poder que existen entre

\footnotetext{
${ }^{1}$ Dice la autora: "Tres características de este sistema de dualismos resultan importantes para la discusión que sigue. Primero, los dualismos están sexualizados. Una mitad de cada dualismo se considera masculina y la otra mitad, femenina. Segundo, los términos de los dualismos no son iguales sino que constituyen una jerarquía. En cada par, el término identificado como "masculino" es privilegiado como superior, mientras que el otro es considerado como negativo, corrupto o inferior. Y tercero, el derecho se identifica con el lado "masculino" de los dualismos" (2009:138).

${ }^{2}$ La otra cara de la crítica feminista reformista establece que para que el derecho sea neutral debe tratar de la misma forma tanto a varones como a mujeres. No estamos de acuerdo con esta postura de corte liberal que no toma en cuenta la subordinación de las mujeres que les impide estar en la misma línea con los varones.
} 
varones y mujeres. Para que el resultado sea igualitario, será necesario contar con previsiones diferenciadas por género.

\section{El derecho a la igualdad material y su vinculación con el acceso a la Justicia}

En el año 1979, gracias a la militancia de las mujeres alrededor del mundo que lograron poner "la cuestión de género" en la agenda pública, la Comunidad Internacional se pronuncia en contra de la discriminación que sufren las mujeres por el hecho de serlo, a través de la firma de la Convención para la eliminación de todas las formas de discriminación contra la mujer, CEDAW (Naciones Unidas, 2008) por sus siglas en inglés. La misma fue ratificada por Argentina en el año 1985. Aunque en 1994 la reforma constitucional argentina nada dijo de manera explícita en su texto sobre la igualdad de mujeres y varones, al incorporar con rango constitucional a la CEDAW a través de su artículo 75 inciso 22, la igualdad ante la ley entre varones y mujeres se vuelve un principio y derecho constitucional en nuestro país.

En el mismo año de la reforma constitucional -1994-, en el ámbito interamericano se firma la Convención Interamericana para Prevenir, Sancionar y Erradicar la violencia contra la mujer -conocida como Convención de Belem do Pará por el lugar de su celebración- que pretende la incorporación de la perspectiva de género en las políticas públicas de los países firmantes en relación con las violencias contra las mujeres. Por nuestro ordenamiento jurídico, la Convención de Belém do Pará ratificada en el año 1996 mediante la ley 24.632, adquiere rango supralegal.

Dado el marco normativo brevemente enunciado, podríamos decir que nuestro país se encuentra comprometido con la igualdad entre varones y mujeres, adscribiendo a la tesis de que es necesario que la legislación contemple las desigualdades que operan en el plano social, pretenda repararlas y no suscriba a la ficción de que alcanza la mera igualdad ante la ley. La intención de este trabajo es analizar si en Argentina logramos trascender la "pesudoneutralidad" legislativa, si puede entenderse a las mujeres como colectivo vulnerable y por qué; y cuál es el alcance de este derecho para las mujeres víctimas de violencias en nuestro país. Para responder estas preguntas es necesario previamente precisar algunos términos. 


\section{Violencias contra las mujeres. Algunas precisiones conceptuales}

Partimos de la base de que es importante tener en cuenta la pluralización de las palabras: violencias y mujeres. Cuando pluralizamos "violencias", queremos dar cuenta de que existen muchos tipos y modalidades de violencias que pueden sufrir las mujeres por el sólo hecho de serlo. Entre ellos, la ley argentina 26.485 de Protección integral para prevenir, sancionar y erradicar la violencia contra las mujeres en los ámbitos en que desarrollen sus relaciones interpersonales reconoce como tipos de violencias ${ }^{3}$ : la violencia física, la psicológica, la sexual, la económica y patrimonial, y finalmente la simbólica. Entre las modalidades ${ }^{4}$ en que estos tipos de violencias se pueden manifestar, enumera: la violencia doméstica, la institucional, la laboral, la violencia contra la libertad reproductiva, la violencia obstétrica y finalmente la violencia mediática. Dicho esto, no sería correcto hablar de violencia cuando se visualizan tantos tipos y modalidades de comisión tan diferentes y variados.

Cuando el plural recae en la palabra "mujer" transformándose en un "mujeres" queremos dar cuenta de que la categoría género aparece como una categoría fundamental para este análisis, pero que no debe dejar de lado las otras categorías que nos atraviesan como seres humanos/as: la edad, la clase social, pertenencia étnica, nacionalidad, color de piel, opción sexual, etcétera, que pueden constituirse o no en marcas de subalternidad. Esto significa que, por ejemplo, no es lo mismo ser una mujer blanca, de clase media y heterosexual, que ser una mujer indígena, lesbiana y extranjera. Todas estas cuestiones que nos particularizan pueden, por ejemplo, facilitarnos o dificultarnos el acceso a determinados derechos.

Además es importante hacer una referencia a la elección del término mujeres víctimas de violencias o mujeres en situación de violencias. Aunque hay quienes (Chejter, Ruffa, 2005) manifiestan que el término mujeres víctimas las cristaliza en un lugar de pasividad, y por ello prefieren la designación "mujeres en situación de violencias", consideramos que al ubicar la palabra víctima como un adjetivo, y no hablar de "víctimas" a secas, no estaría cristalizando a las mujeres que atraviesan este tipo de situaciones en un lugar pasivo, sino dando una característica, entre muchas otras, que tiene esa mujer en un momento y lugar determinado.

\footnotetext{
${ }^{3}$ Ley 26.485 art. $5^{\circ}$.

${ }^{4}$ Ley 26.485 art. $6^{\circ}$.
} 
Además, tanto las legislaciones nacionales como internacionales hablas de mujeres víctimas como condición para el acceso a determinados derechos.

Sí es necesario decir que las mujeres que atraviesan situaciones de violencias jamás son personas pasivas, todo lo contrario: son capaces de atravesar las "rutas más críticas" para salir de la violencia en la que se encuentran inmersas. Las mujeres resisten mucho las violencias que sufren y en relación con ello debemos precisar otros dos términos fundamentales para poder comprender cabalmente la problemática del acceso a la Justicia para mujeres víctimas de violencias: victimización secundaria y "ruta crítica".

El concepto de victimización secundaria se refiere a aquella victimización que es producida por los organismos del Estado que, encargados de mitigar los efectos de una acción dañosa (victimización primaria) en realidad los profundizan. Esta profundización puede manifestarse en esperas muy largas, falta de sensibilidad en relación con la temática, falta de perspectiva de género en las actuaciones y respuestas, entre otras. En relación a las mujeres víctimas de violencias, esta victimización secundaria se constituye en uno de los principales obstáculos para el acceso a la Justicia, como veremos seguidamente.

El concepto de victimización secundaria está íntimamente ligado con el de "ruta crítica" que se puede definir como el itinerario que deben recorrer las mujeres en situación de violencia por diferentes instituciones públicas y privadas (organismos del sistema de salud, desarrollo social, áreas de género, comisarías, tribunales, organizaciones sociales, etcétera) para lograr un efectivo acceso a la Justicia. En palabras de Sargot, citada por Delmas y Urtazún:

"La Ruta Crítica nos abre una puerta y nos lleva por los caminos que toman las mujeres para salir de su situación de violencia. La Ruta empieza con la decisión y determinación de las mujeres de apropiarse de sus vidas y las de sus hijos. Siguiendo esta Ruta, conocemos los factores que impulsan a las mujeres a buscar ayuda, las dificultades encontradas para llevar adelante tal decisión, sus percepciones sobre las respuestas institucionales, y las representaciones sociales y significados sobre la violencia intrafamiliar que existen entre el personal de las instituciones que deben ofrecer respuestas a este serio problema de salud pública. Al fin, aprendemos sobre sus frustraciones y resignaciones que, en muchos casos, las llevan otra vez a la situación de violencia" (Delmas, Urtazún, 2012:11). 


\section{Acceso a la Justicia para mujeres víctimas de violencias. Definición y marco legal}

Entendemos que las apreciaciones sobre acceso a la Justicia son aplicables tanto para mujeres como para varones, pero la inclusión de la perspectiva de género ${ }^{5}$ al análisis permite visibilizar el impacto diferencial para unos y para otras de algunas políticas públicas que se pretenden neutrales en cuanto al género. Dicha neutralidad es una ficción desde que la desigualdad de género es la base del sistema patriarcal ${ }^{6}$ en el que estamos inmersos/as y el cual se fundamenta precisamente en la desigualdad entre varones y mujeres, otorgándole privilegios a los primeros en detrimento de las segundas.

De acuerdo al Informe de la Comisión Interamericana de Derechos Humanos Acceso a la justicia para las mujeres víctimas de violencia en las Américas de 2007, se define acceso a la Justicia como:

“[...] el acceso de jure y de facto a instancias y recursos judiciales de protección frente a actos de violencia, de conformidad con los parámetros internacionales de derechos humanos. La CIDH ha establecido que un acceso adecuado a la justicia no se circunscribe sólo a la existencia formal de recursos judiciales, sino también a que éstos sean idóneos para investigar, sancionar y reparar las violaciones denunciadas" (OEA, 2007:3).

\footnotetext{
${ }^{5}$ Entendemos que la perspectiva de género implica: “a) reconocer las relaciones de poder que se dan entre los géneros, en general favorables a los varones como grupo social y discriminatorias para las mujeres; b) que dichas relaciones han sido constituidas social e históricamente y son constitutivas de las personas; c) que las mismas atraviesan todo el entramado social y se articulan con otras relaciones sociales, como las de clase, etnia, edad, preferencia sexual y religión. La perspectiva de género opta por una concepción epistemológica que se aproxima a la realidad desde las miradas de los géneros y sus relaciones de poder. Sostiene que la cuestión de los géneros no es un tema a agregar como si se tratara de un capítulo más en la historia de la cultura, sino que las relaciones de desigualdad entre los géneros tienen sus efectos de producción y reproducción de la discriminación, adquiriendo expresiones concretas en todos los ámbitos de la cultura: el trabajo, la familia, la política, las organizaciones, el arte, las empresas, la salud, la ciencia, la sexualidad, la historia. La mirada de género no está supeditada a que la adopten las mujeres ni está dirigida exclusivamente a ellas. Tratándose de una cuestión de concepción del mundo y de la vida, lo único definitorio es la comprensión de la problemática que abarca y su compromiso vital" (Gamba, 2007:120-121).

${ }^{6}$ Tomaremos la definición de Patriarcado de Heidi Hartmann que lo define como "un conjunto de relaciones sociales que tiene una base material y en el que hay unas relaciones jerárquicas y una solidaridad entre los hombres que les permiten dominar a las mujeres. La base material es el control del hombre sobre la fuerza de trabajo de la mujer" (Hartmann, 1980:97).
} 
El concepto de acceso a la Justicia puede definirse entonces en sentido amplio o en sentido estricto. En sentido amplio, se considera acceso a la Justicia cuando las mujeres pueden acceder a todos aquellos servicios y dispositivos que trabajan con la problemática de las violencias contra las mujeres sin sufrir una re-victimización y obteniendo una respuesta adecuada. Esto significa que el acceso a la Justicia se materializa no sólo con el acceso a los tribunales, sino también al servicio de salud, a las prestaciones sociales, a programas de inclusión laboral, etcétera. En sentido estricto, y de acuerdo con el informe citado, el acceso a la Justicia se traduce en arribar al sistema judicial con patrocinio letrado y disponer de un buen servicio de Justicia del que se pueda obtener un pronunciamiento justo. Garantizar el derecho al acceso a la Justicia pretende disminuir la brecha, denunciada por Birgin y Kohen, "entre los derechos que el sistema legal reconoce a las personas y grupos sociales y la posibilidad de ejercicio efectivo de los mismos, en especial para los ciudadanos de menores recursos económicos" (2006:23).

De acuerdo al Informe de la Organización de Estado Americanos citado, se manifiesta que "el deber de los Estados de proveer recursos judiciales no se limita a una disponibilidad formal, sino que tales recursos deben ser idóneos para remediar las violaciones de derechos humanos denunciadas" (OEA, 2007: viii).

Como premisa de esta conceptualización de acceso a la Justicia, podemos pensar en la necesidad de que las mujeres tengan un conocimiento efectivo de sus derechos. Para ello y para acceder a los órganos jurisdiccionales adecuadamente, es necesario entonces la alfabetización jurídica de las mujeres, y la simplificación del lenguaje tribunalicio para achicar la distancia que existe entre los/as operadores/as judiciales y la población en general. Además quienes necesitan una respuesta en cuanto a la vulneración de sus derechos deben poder sostener el proceso en cuestión, que muchas veces puede dificultarse no sólo por la "ruta crítica" que deben recorrer las mujeres en su pedido de restablecimiento de sus derechos, sino también los costos que el proceso puede asumir, que no se subsanan sólo a través de un beneficio de litigar sin gastos o de un patrocinio jurídico gratuito -que sí resultan imprescindibles como punto de partida-, ya que estas medidas no cubren los gastos de traslados ni los costos de los tiempos de espera, o el cuidado de los/as niños/as mientras la mujer deambula por tribunales. Es entonces pertinente citar a Natalia Gherardi cuando afirma (2006: 134): 
"El acceso de la justicia, entonces, puede ser considerado desde tres aspectos diferenciados aunque complementarios entre sí: (i) el acceso propiamente dicho, es decir, la posibilidad de llegar al sistema judicial; (ii) la posibilidad de lograr un buen servicio de justicia, es decir, no sólo llegar al sistema sino que éste brinde la posibilidad de lograr un pronunciamiento judicial justo en un tiempo prudencial; y (iii) por último, necesariamente complementario de los aspectos anteriores, es el conocimiento de los derechos por parte de los ciudadanos, de los medios para poder ejercer y hacer reconocer esos derechos y específicamente la conciencia del acceso a la justicia como un derecho y la consiguiente obligación del Estado de brindarlo y promoverlo".

Entre los tratados internacionales incorporados con rango constitucional en la última reforma de la Constitución argentina del año 1994 que receptan el acceso a la justicia como derecho humano, podemos citar a la Declaración Universal de Derechos Humanos (art. 8 y 10), el Pacto Internacional de Derechos Civiles y Políticos (art. 2.3), la Declaración Americana de los Derechos y Deberes del Hombre (art. 26 y 28), y la Convención Americana sobre Derechos Humanos (art. 8.1).

Puntualmente en relación con las mujeres, la CEDAW que data de 1979 establece en su artículo segundo la obligación de los Estados a erradicar la discriminación contra las mujeres, la cual entendemos la causa última de las violencias de género mediante la consagración del principio de igualdad entre los sexos en la Constitución y la aseguración "por ley u otros medios apropiados la realización práctica de ese principio" (inciso a). También es pertinente citar el inciso c del mismo artículo que manda a los Estados a "establecer la protección jurídica de los derechos de la mujer sobre una base de igualdad con los del hombre y garantizar, por conducto de los tribunales nacionales competentes y de otras instituciones públicas, la protección efectiva de la mujer contra todo acto de discriminación".

La CEDAW también establece la posibilidad de la adopción de medidas de acción positiva $^{7}$ que coadyuven a consolidar la igualdad entre mujeres y varones (artículo 4$)^{8}$. En el

\footnotetext{
${ }^{7}$ Se entiende por medida de acción positiva las "medidas dirigidas a un grupo determinado, con las que se pretende suprimir y prevenir una discriminación o compensar las desventajas resultantes de actitudes, comportamientos y estructuras existentes (denominadas a veces "discriminación positiva")" (Comisión Europea, 1998 , disponible en http://www.europarl.europa.eu/transl es/plataforma/pagina/celter/glosario genero.htm -recuperado el $10 / 01 / 2015)$.
} 
ámbito interamericano, la Convención de Belem do Pará establece en su artículo séptimo inciso b, que entre las obligaciones de los Estados firmantes se encuentra el "actuar con la debida diligencia para prevenir, investigar y sancionar la violencia contra la mujer" como una garantía del acceso a la Justicia para las mujeres víctimas de violencias.

Veinticuatro años después de la ratificación de la CEDAW por nuestro país y quince años después de la firma de la Convención de Belem do Pará, la ley argentina 26.485 de 2009 operacionaliza los derechos consagrados a nivel internacional en el territorio.

La ley 26.485 establece un procedimiento especializado para casos de violencias de género: "Sea cual fuera el orden jurisdiccional en donde se radique una cuestión de violencia de género, debe aplicarse el mismo procedimiento sumarísimo que establece la ley" (Cano, 2012:138). Como se trata de un procedimiento especializado, se establecen los principios que deben guiarlo, independientemente del fuero que tramite la cuestión, que se traducen en los siguientes derechos para las mujeres (entre otros):

- la gratuidad del procedimiento y el patrocinio jurídico especializado,

- el derecho a obtener una respuesta jurisdiccional oportuna y efectiva,

- el derecho de la mujer a ser oída durante el proceso y que su opinión sea tenida en cuenta al momento de resolver,

- el derecho a recibir protección judicial urgente y preventiva,

- el derecho a recibir información del procedimiento y a no sufrir re-victimización (o victimización secundaria).

Dicho reconocimiento a los derechos de las mujeres durante el procedimiento por el que se tramite su derecho a vivir una vida libre de violencias es un claro ejemplo de las medidas que deben adoptarse para que las mujeres puedan efectivamente acceder a la Justicia, lo que en sentido restrictivo significa: acceder a los tribunales de Justicia, sostener la petición y poder obtener una respuesta jurisdiccional justa.

${ }^{8}$ Dice el artículo $4^{\mathrm{o}}$ de la CEDAW: "La adopción por los Estados Partes de medidas especiales de carácter temporal encaminadas a acelerar la igualdad de facto entre el hombre y la mujer no se considerará discriminación en la forma definida en la presente Convención, pero de ningún modo entrañará, como consecuencia, el mantenimiento de normas desiguales o separadas; estas medidas cesarán cuando se hayan alcanzado los objetivos de igualdad de oportunidad y trato" (Naciones Unidas, 2008:6). 
Por todo ello, también el procedimiento impone la amplia libertad probatoria, posibilidad de los/as jueces/zas de impulsar de oficio el procedimiento e incluso "la posibilidad que le asiste al mismo/a de solicitar un informe (que debe ser remitido dentro de las 48 horas de solicitado) efectuado por un equipo interdisciplinario para determinar los daños físicos, psicológicos, económicos o de otro tipo sufridos por la mujer y la situación de peligro en la que se encuentre" (Cano, 2012: 99).

Retomando el hilo propuesto por Frances Olsen (2009) y el análisis de la normativa que intentar garantizar el acceso a la Justicia para mujeres víctimas de violencias, podemos pensar en que la legislación argentina intenta paliar la "pseudoneutralidad" denunciada por el feminismo, y entonces nos preguntamos: ¿constituyen las mujeres un colectivo vulnerable?

\section{Las mujeres víctimas de violencias como colectivo en situación de vulnerabilidad}

¿Puede pensarse a las mujeres como un colectivo vulnerable? La ley 26.485 claramente aboga por la construcción de una igualdad material, considerando como colectivo vulnerable a las mujeres víctimas de violencias pero esta consideración no es un invento argentino. En el año 2008 en la XIV Cumbre judicial iberoamericana consensua las Reglas de Brasilia sobre acceso a la Justicia de las personas en condición de vulnerabilidad cuyo objetivo es la garantía de las "condiciones de acceso efectivo a la justicia de las personas en condición de vulnerabilidad, sin discriminación alguna, englobando el conjunto de políticas, medidas, facilidades y apoyos que permitan a dichas personas el pleno goce de los servicios del sistema judicial" (Capítulo 1, Sección 1, párr. 1).

La Reglas, dirigidas a los/as operadores/as del sistema judicial y funcionarios/as públicos/as encargados del diseño de políticas de Estado, estipulan que se entenderá que ostentan condiciones de vulnerabilidad los colectivos de personas que "encuentran especiales dificultades para ejercitar con plenitud ante el sistema de justicia los derechos reconocidos por el ordenamiento jurídico" (Capítulo 1, Sección 2.1, párr. 3). El género se encuentra entre las causas de dicha vulnerabilidad, y puntualmente establece: 
"La discriminación que la mujer sufre en determinados ámbitos supone un obstáculo para el acceso a la justicia, que se ve agravado en aquellos casos en los que concurra alguna otra causa de vulnerabilidad. Se entiende por discriminación contra la mujer toda distinción, exclusión o restricción basada en el sexo que tenga por objeto o resultado menoscabar o anular el reconocimiento, goce o ejercicio por la mujer, independientemente de su estado civil, sobre la base de la igualdad del hombre y la mujer, de los derechos humanos y las libertades fundamentales en las esferas política, económica, social, cultural y civil o en cualquier otra esfera" (Capítulo 1, Sección 2.8, párr. 17 y 18).

Las Reglas también se encargan de definir a la violencia contra la mujer ${ }^{9}$ y establece que se debe prestar especial atención a los supuestos de mujeres víctimas de violencias "estableciendo mecanismos eficaces destinados a la protección de sus bienes jurídicos, al acceso a los procesos judiciales y a su tramitación ágil y oportuna" (Capitulo 1, Sección 2, párr. 20).

Teniendo en cuenta lo previamente expuesto, las mujeres no constituyen per se un colectivo vulnerable, pero su situación de subordinación en el marco de una sociedad patriarcal que las hace pasibles de ser víctimas de violencias por el sólo hecho de ser mujeres, sí las coloca en un estado de vulnerabilidad que las leyes no pueden obviar si pretenden que la igualdad entre varones y mujeres sea un hecho. También es necesario relevar cuáles son los obstáculos que las mujeres encuentran en su búsqueda de Justicia para poder por fin determinar el alcance del derecho al acceso a la Justicia para las mujeres víctimas de violencias.

\section{Obstáculos para el acceso a la Justicia para mujeres víctimas de violencias}

Es importante analizar el acceso a la Justicia y los obstáculos que a ella se presentan con perspectiva de género, ya que ésta perspectiva analítica develará la distribución desigual de poder entre mujeres y varones, y cómo muchas veces el derecho consolida las desigualdades existentes.

\footnotetext{
9 "Se considera violencia contra la mujer cualquier acción o conducta, basada en su género, que cause muerte, daño o sufrimiento físico, sexual o psicológico a la mujer, tanto en el ámbito público como en el privado, mediante el empleo de la violencia física o psíquica” (Capítulo 1, Sección 2, párr.19).
} 
"Si bien varios de los obstáculos para el acceso a la justicia son comunes a todos los justiciables, independientemente de su origen social, es indudable que esos obstáculos resultan mucho más difíciles de superar para los grupos más pobres y, en particular, para las mujeres por su condición de subordinación. La justicia parte de un concepto abstracto de igualdad que no da cuenta cabal del contexto social, histórico, cultural, económico, de género, etc.” (Birgin y Kohen, 2006b: 239).

Dichos obstáculos pueden ser del orden de los costos económicos de los procesos, la falta de información sobre los derechos y los procedimientos para ejercerlos, la corrupción de los órganos jurisdiccionales que se relaciona íntimamente con el miedo y desconfianza que suscitan en la población, el formalismo judicial, las demoras excesivas de los procedimientos y la ubicación geográfica de los tribunales, entre otros (Gherardi, 2006).

Para las mujeres víctimas de violencias las trabas al acceso al restablecimiento de sus derechos son sistematizadas por la Comisión Interamericana como retrasos injustificados en las diligencias necesarias por parte de las instancias encargadas de efectuar la investigación, y vacíos e irregularidades en las diligencias que obstaculizan el proceso de juzgamiento y la sanción eventual de los casos (OEA, 2007: ix):

Si bien la Comisión reconoce los esfuerzos de los Estados por adoptar un marco jurídico y político que permita abordar la violencia contra las mujeres, aún persiste una enorme distancia entre la disponibilidad formal de ciertos recursos y su aplicabilidad efectiva. La mayoría de los casos de violencia contra las mujeres no son formalmente investigados, juzgados y sancionados por los sistemas de administración de justicia en el hemisferio (OEA, 2007: viii).

La brecha existente entra la gravedad del problema y la respuesta ofrecida se traduce en impunidad. El mensaje de la prevalencia de la misma es claro: en las mujeres implica un llamamiento a que se adecuen a los roles de género prescritos sino les puede costar la vida, y a los varones una ratificación del statu quo patriarcal que los sitúa en la parte superior del par dual. La impunidad propicia la repetición crónica de las violación a los derechos, y una sensación de impotencia y desamparo en las víctimas (OEA, 2007).

Es perentorio registrar que la impunidad de los agresores sexistas se relaciona con la falta de una adecuada investigación y sanción de los delitos cometidos. En ciertos países de Latinoamérica, muchas veces son más graves y más perseguidos y penalizados los delitos contra la propiedad que los delitos contra las vidas e integridad psicofísica de las mujeres. De 
esta manera se construye ese imaginario que tolera y acepta las violencias contra las mujeres, naturalizando el sometimiento de éstas y naturalizando también, la desconfianza de las mismas con respecto a las instituciones estatales que deberían protegerlas.

No se trata solamente de la insistencia de las instituciones estatales y del imaginario colectivo de considerar esta problemática como del ámbito privado, sino la creencia de que el Estado no debe meterse "más allá de la puerta del hogar" cuando los Estados de todo tipo y color se han caracterizado por regular las cuestiones del ámbito privado desde el principio de los tiempos, y basta echarle una mirada a los códigos civiles de mitad de siglo pasado para constatarlo. Entonces ¿por qué cuando se trata de violencias contra las mujeres se esgrime este argumento falaz? Evidentemente existe una intención de mantener cierto orden de cosas, de sostener el contrato sexual (Pateman, 1995) que explica la dominación masculina ${ }^{10}$ :

"La Comisión ha constatado que ciertos patrones socioculturales discriminatorios influyen en las actuaciones de los funcionarios en todos los niveles de la rama judicial, lo que se traduce en un número aún ínfimo de juicios orales y sentencias condenatorias que no corresponden al número elevado de denuncias y a la prevalencia del problema. La CIDH ha podido verificar que la violencia y la discriminación contra las mujeres todavía son hechos aceptados en las sociedades americanas, lo cual se ve reflejado en la respuesta de los funcionarios de la administración de la justicia hacia las mujeres víctimas de violencia y en el tratamiento de los casos. Existe asimismo una tendencia a considerar los casos de violencia contra las mujeres como conflictos domésticos, privados y no prioritarios que deben ser resueltos sin la intervención del Estado" (OEA, 2007:6).

Hay que tener presente que cuando un/a funcionario/a le dice, implícita o explícitamente a una mujer víctima de violencia, que su problema no es importante, intenta disuadirla, intenta convencerla de que se vaya a su casa a prepararle una comida rica a su marido y/o la culpa por la violencia sufrida, este acto se percibe como mucho más grave; porque no es el/la funcionario/a quien habla, sino el Estado. Teniendo ello en cuenta, nos preguntamos: ¿Concurren las mujeres a los órganos jurisdiccionales para reclamar por la vulneración de sus derechos?

\footnotetext{
10 "La dominación de los varones sobre las mujeres y el derecho de los varones a disfrutar de un igual acceso sexual a las mujeres es uno de los puntos en la firma del pacto original. El contrato social es una historia de libertad, el contrato sexual es una historia de sujeción" (Pateman, 1995:10).
} 
"El problema de la falta de información sobre los recursos judiciales disponibles y el hecho de que la violencia y la discriminación contra las mujeres todavía sean hechos aceptados en las sociedades americanas, dan como resultado un reducido número de denuncias de actos de violencia contra las mujeres. El problema ha sido descrito por la red ISIS Internacional en los siguientes términos: Se constata que existe desconocimiento de sus derechos por parte de las mujeres. En general las mujeres, en particular las de escasos recursos, desconocen sus derechos y los mecanismos existentes para hacerlos valer. La violencia en contra de las mujeres sigue siendo una práctica extendida, aceptada culturalmente, frente a lo cual las normas aparecen como una medida regulatoria, pero que no aseguran por sí solas el cambio cultural que es necesario para erradicarlas" (OEA, 2007:98).

De acuerdo a la OEA entonces, algunas mujeres sí concurren a tribunales en pos del restablecimiento de sus derechos humanos vulnerados, pero muchísimas otras no. Además de las razones que esgrimimos en párrafos anteriores, ¿cuáles pueden ser los motivos por los cuales las mujeres no concurren a los tribunales para demandar por Justicia y adecuada reparación por sus derechos humanos vulnerados? No existe una única respuesta sino un conglomerado de situaciones que nos pueden explicar esta reticencia, como venimos esgrimiendo en los párrafos precedentes: la doble victimización o victimización secundaria, la falta de medidas efectivas de protección, el costo económico, y el desconocimiento de sus derechos y de los mecanismos para hacerlos valer (OEA, 2007). Además hay un factor extra: la estigmatización que sufren las mujeres que denuncian. Nótese que estos obstáculos no sólo afectan a las mujeres en situación de pobreza, sino a las mujeres por ser mujeres en general situación que obviamente se agrava en situaciones de pobreza, marginalidad, etnicidad, color de piel, etcétera-.

Es necesario tener presente cómo los recursos humanos de las instituciones pueden determinar la calidad de la atención. Una mala atención no se debe sólo a deficiencias de infraestructura, la sobrecarga de tareas, la falta de personal, la inexistencia de presupuesto cuestiones que obstan a una correcta atención-, sino también es evidente la falta de capacitación y sensibilización de los agentes en la problemática de las violencias contra las mujeres.

“Tanto la Corte Interamericana como la CIDH han afirmado reiteradamente que la investigación de casos de violaciones de los derechos humanos, que incluye los casos de violencia contra las 
mujeres, deben llevarse a cabo por autoridades competentes e imparciales. Cuando tales investigaciones no son llevadas a cabo por autoridades apropiadas y sensibilizadas en materia de género o estas autoridades no colaboran entre sí, se registran retrasos y vacíos clave en las investigaciones, que afectan negativamente el futuro procesal del caso" (OEA, 2007:21).

Entre los problemas estructurales que obstaculizan el acceso a la Justicia detectados por la CIDH se enuncian:

“[...] la ausencia de instancias de la administración de la justicia en zonas rurales, pobres y marginadas; la falta de abogados de oficio para las víctimas de violencia que no cuentan con recursos económicos; la falta de recursos humanos y financieros para atender los problemas persistentes y estructurales; la debilidad institucional de los ministerios públicos y la policía que investigan los delitos; y la falta de unidades especiales dentro de las fiscalías, la policía y los tribunales con destreza técnica y conocimientos especiales. Otro obstáculo relevante es la precariedad y descoordinación en los sistemas de información para recopilar estadísticas sobre incidentes y casos de violencia contra las mujeres, indispensable para analizar posibles causas y tendencias y evaluar la respuesta del sistema de justicia ante actos de violencia contra las mujeres" (OEA, 2007:78).

\section{Reflexiones finales}

Aunque el ordenamiento jurídico argentino recepta disposiciones internacionales a favor de la igualdad entre varones y mujeres, y además sanciona sus propias leyes para cumplir cabalmente con el objetivo de garantizar a las mujeres el derecho a una vida libre de violencias, la igualdad en nuestro país sigue operando sólo en un plano formal. De adecuado a un informe del Observatorio de Femicidios "Adriana Marisel Zambrano"12, en el periodo que va del año

\footnotetext{
11 "El término femicidio es la traducción de la voz inglesa femicide, conceptualizada por Diana Russell como "el asesinato de mujeres por hombres por ser mujeres" (Russell, 2005:137). Esta construcción se hizo necesaria al notar que el asesinato de mujeres por el sólo hecho de serlo no era una actitud aislada, o un dato individual, sino que se daba de manera a-histórica y a-cultural en todas las sociedades del mundo, de una manera sistematizada y con un alto grado de impunidad para encontrar y penar a los responsables" (Cano, Yacovino, 2013:1-2).
} 
2008 al año 2012 se registraron 1223 femicidios y femicidios "vinculados" 13 de mujeres y niñas, 99 femicidios "vinculados" de varones y niños y 1520 hijas e hijos de mujeres asesinadas por violencia de género como víctimas colaterales (Rico et al., 2013:65) y para el año 2013 la cifra fue de 295 femicidios y femicidios "vinculados" de mujeres y niñas y 39 femicidios "vinculados" de varones y niños. De acuerdo a estos datos, cada 30 horas se mata a una mujer en Argentina, por el sólo hecho de ser mujer.

Desde la sanción de la ley 26.485 en el año 2009 y a partir de una serie de femicidios que pusieron el tema en la agenda pública, el Congreso de la Nación sancionó una serie de leyes penales para abordar la problemática de las violencias y desnaturalizar las violencias de género. Así fue que se incluyó el delito de femicidio en el Código Penal en $2012^{14}$, la supresión en el mismo año de la figura del avenimiento ${ }^{15}$, la modificación de la ley para la Prevención y Sanción de la Trata de Personas y Asistencia a sus Víctimas ${ }^{16}$ (también en 2012) y la creación del Registro Nacional de Datos Genéticos vinculados con delitos sexuales ${ }^{17}$ en el año 2013. Aun así, ser mujer sigue siendo una situación de riesgo en nuestro país.

También la Corte Suprema de Justicia de la Nación consideró que la admisión de la suspensión del juicio a prueba en causas sobre violencias contra las mujeres vulnera su derecho al acceso a la Justicia que se consagra a partir de la firma de la Convención de Belem do Pará. Desde el fallo de la Corte "Góngora", aplicar este instituto en las causas penales en donde las mujeres sean las víctimas.

\footnotetext{
${ }^{12}$ Debido a que no existen estadísticas oficiales en el territorio, debemos valernos del informe: "Por Ellas...5 años de informes de femicidios" realizado por un Observatorio específico de una Asociación Civil. Este informe abarca un rango de fechas desde el 01/01/2008 al 31/12/2012. Las fuentes de información son las agencias informativas: Télam y DyN y 120 diarios de distribución nacional y provincial. Además se realiza un seguimiento de casos en los medios, sobre todo cuando: "la descripción del asesinato evidencia elementos de violencia de género (...); existen indicios claros y evidentes de violencia sexual, violación y/o abuso; el asesinato no se enmarca en un caso de inseguridad convencional (robo, hurto, etc.)" (Rico et al., 2013:65).

${ }^{13}$ La Casa del Encuentro define "femicidio vinculado" como aquel femicidio que tiene como objetivo "matar, castigar o destruir psíquicamente a la mujer sobre la cual ejerce la dominación. En esta definición se registran dos categorías: 1. Personas que fueron asesinadas por el femicida, al intentar impedir el Femicidio o que quedaron atrapadas "en la línea de fuego"; 2. Personas con vínculo familiar o afectivo con la mujer, que fueron asesinadas por el femicida con el objeto de castigar y destruir psíquicamente a la mujer a quien consideran de su propiedad" (Rico et al., 2013:27).

${ }_{14}^{14}$ Ley 26.791. Sancionada el 14/11/2012. Promulgada el 11/12/2012.

${ }^{15}$ Ley 26.738. Sancionada: 21/03/2012. Promulgada: 04/04/ 2012.

${ }^{16}$ Ley 26.842. Sancionada el 19/12/2012. Promulgada el 26/12/2012.

${ }^{17}$ Ley 26.879. Sancionada: 03/07/2013. Promulgada: 23/07/2013.

18 "Góngora, Gabriel Arnaldo s/ causa n 14.092" CJSN, 30/04/2014.
} 
Podemos pensar que las últimas reformas legislativas en Argentina trascienden la “pseudoneutralidad" legislativa denunciada por el feminismo y receptada por Olsen (2009) dando cuenta cómo el sistema patriarcal es la primera causa de que las mujeres víctimas de violencias se constituyan como un colectivo vulnerable. Si entendemos que la causa de las violencias es la persistencia de un ideario patriarcal que sitúa a las mujeres en un lugar de inferioridad con respecto a los varones, que las cosifica y trasmite el mensaje de que somos propiedad de los varones, y las leyes sancionadas no alcanzan para remover el obstáculo para el acceso a la Justicia, deberemos volver a la premisa básica de la reforma educativa.

Ya no se trata solamente de la sensibilización de la opinión pública al respecto (Cano, 2012) sino de la formación concreta de los/as funcionarios/as que en primera instancia trabajan con esta problemática (jueces/zas, fiscales, defensores, abogados/as de la matrícula, etcétera) y paralelamente alfabetizar jurídicamente y en sus derechos a las mujeres. Más profundamente, en tanto y en cuanto no contemos con una currícula educativa que aborde la equidad de género como algo fundamental, y que este tema no esté abordado por profesionales que tengan perspectiva de género, las medidas adoptadas, aunque son importantes, no serán más que parches. Tener presente que para desestabilizar el sistema patriarcal debemos desmantelar las trincheras, en términos gramscianos, del mismo es vital para lograr con éxito el cometido de la igualdad.

Las leyes consagratorias de derechos son el primer gran logro de las luchas feministas, y las leyes que entienden que las mujeres integrar un colectivo vulnerable yendo más allá de la "pseudoneutralidad" que se cristaliza en una igualdad meramente formal, son un éxito inconmensurable. Sin embargo, la igualdad sigue siendo una meta a lograr en tanto y en cuanto no podemos, como mujeres, trascender la vulnerabilidad en la que nos ubica el patriarcado a partir de una educación realmente comprometida con la igualdad. 


\section{BIBLIOGRAFÍA}

- Birgin, Haydee y Kohen, Beatriz (2006): "Introducción. El acceso a la Justicia como derecho”. En Haydee Birgin y Beatriz Kohen (comp.): Acceso a la justicia como garantía de igualdad. Instituciones, actores y experiencias comparadas. Buenos Aires: Biblos. Colección "Identidad, mujer y derecho".

- Birgin, Haydee y Kohen, Beatriz (2006b): “Justicia y Género, una experiencia en la ciudad de Buenos Aires”. En Haydee Birgin y Beatriz Kohen (comp.): Acceso a la justicia como garantía de igualdad. Instituciones, actores y experiencias comparadas. Buenos Aires, Biblos, Colección "Identidad, mujer y derecho".

- Cano, Julieta (2012): "Violencia de género. Comparación entre la ley española 1/2004 y la ley argentina $\mathrm{N}^{\mathrm{0}}$ 26.485”. Tesis de Maestría. Universidad de Salamanca, España. Publicado por el Repositorio Documental de la Universidad de Salamanca, [en línea] Disponible en: http:/gredos.usal.es/jspui/handle/10366/122168 [30/09/2013].

- Cano, Julieta y Yacovino, María Laura (2013): "Historias de “amor", machismo y muerte". En: Las Actas de las III Jornadas del CINIG, [en línea] Disponible en: http://jornadascinig.fahce.unlp.edu.ar/iii-2013 - ISSN: 2250-5695.La Plata, FAHCE-UNLP, 25 al 27 de septiembre de 2013.

- Naciones Unidas (2008): “CEDAW - Convensión sobre la eliminación de todas las formas de discriminación contra la mujer", [en línea] Disponible en: http://www.un.org/womenwatch/daw/cedaw/text/sconvention.htm [12/05/2014].

- Comisión Europea (1998): 100 palabras para la igualdad. Glosario de términos relativos a la igualdad entre hombres y mujeres. Dirección General de Empleo, Relaciones Laborales y Asuntos Sociales.

- Delmas, Flavia y Urtazún, Celina (2012): "Recorridos, vacíos institucionales y estrategias frente a la violencia contra las mujeres". Ponencia presentada en: Las VI I Jornadas de Sociología de la UNLP “Argentina en el escenario latinoamericano actual: Debates desde las ciencias sociales” La Plata, 5, 6 y 7 de diciembre de 2012.

- Gamba, Susana (2007): Diccionario de estudios de género y feminismos. Buenos Aires, Editorial Biblós. 
- Gherardi, Natalia (2006): "Notas sobre acceso a la justicia y servicios jurídicos gratuitos en experiencias comparadas: ¿un espacio de asistencia posible para las mujeres?”. En: Haydee Birgin y Beatriz Kohen (comp.): Acceso a la justicia como garantía de igualdad. Instituciones, actores y experiencias comparadas. Buenos Aires: Biblos, Colección "Identidad, mujer y derecho".

- Hartmann, Heidi (1980): “Un matrimonio mal avenido, hacia una unión más progresiva entre feminismo y marxismo". En. Zona Abierta, No. 24. pp.85-113.

- OEA (2007): "Informe de la Comisión Interamericana de Derechos Humanos Acceso a la justicia para las mujeres víctimas de violencia en las Américas”, OEA/Ser.L/V/II. Doc. 68.

- Olsen, Frances (2009): "El sexo del derecho”. En Ramiro Ávila Santamaría; Judith Salgado y Lola Valladares (Comps.): El género en el derecho. Ensayos críticos. Ecuador: Ministerio de Justicia y Derechos Humanos.

- Pateman, Carole (1995): El Contrato Sexual, México: Anthopos/UAM

- Rico, Ada et al. (2013) (dir.): Por Ellas... 5 años de Informes de Femicidios. $1^{\circ}$ Ed. Buenos Aires: La Casa del Encuentro.

\section{NORMATIVAS CITADAS}

- Ley 24.632 (1996) “Aprobación de la Convención Interamericana para Prevenir, Sancionar y Erradicar la violencia contra la mujer".

- Ley 26.485 (2009) "De protección integral para prevenir, sancionar y erradicar la violencia contra las mujeres en los ámbitos en que desarrollen sus relaciones interpersonales".

- Ley 26.791 (2012) Modificación del Código Penal argentino. Tipificación del femicidio.

- Ley 26.738 (2012) Modificación del Código Penal argentino. Supresión de la figura de avenimiento.

- Ley 26.842 (2012) "Prevención y sanción de la trata de personas y asistencia a sus víctimas".

- Ley 26.879 (2013) “Creación del registro nacional de datos genéticos”. 